\title{
Organisational commitment, work engagement and meaning of work of nursing staff in hospitals
}

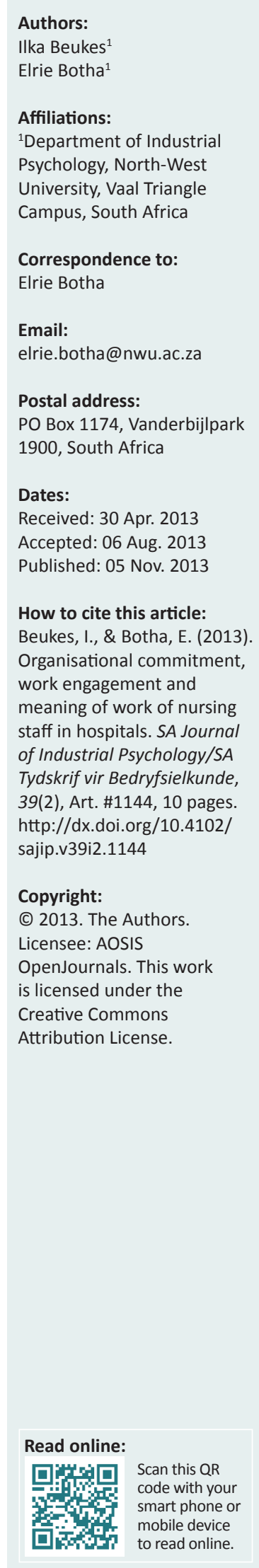

Orientation: Nursing is a noble profession but not always an easy job. Work overload, few resources, limited promotion and development opportunities have a negative impact on the sustainability of the profession.

Research purpose: The primary objective of this research was to investigate the relationship between organisational commitment, work engagement and meaning of work amongst nursing staff at various hospitals.

Motivation for study: It is important to understand how to optimise the work experience of nursing staff in order to ensure a committed and engaged workforce.

Research design, approach and method: A survey design with a cluster sample $(n=199)$ was used. The Organisational Commitment Questionnaire, Utrecht Work Engagement Scale, Work-Life Questionnaire and a biographical questionnaire were administered.

Main findings: The majority of the scales showed acceptable reliability. Results indicated that the majority of nursing staff view their work as either a job or a calling. This impacts the organisation in the sense that viewing work as a calling predicts $19 \%$ of the variance in organisational commitment and $30 \%$ of the variance in work engagement.

Practical/managerial implications: Viewing work as a calling will accompany higher levels of engagement and commitment to the organisation. Nurses who feel that they make a meaningful contribution to the hospital are more inclined to stay in the organisation.

Contribution/value-add: Strategies can be put in place to focus on experiencing work as a calling, rather than a job. Enhancing this experience and creating awareness could lead to higher levels of organisational commitment and work engagement.

\section{Introduction}

South Africa is becoming a more interdependent and interconnected country and, as a result, the mobility of skilled personnel is increasing (Pillay, 2009). Health care systems are also affected by health professionals moving out of the market, leading to adverse consequences for the country. Taking into consideration the role played by nursing staff in the effectiveness and sustainability of the country's health care systems, it is of considerable importance to understand the organisational and personal variables that motivate them to stay in their field and within a specific organisation (Pillay, 2009). Jacobs and Roodt (2007) proposed that, since financial constraints, exchange rates and tax-free salaries at times make it difficult for local hospitals to compete with offerings from international competitors, their retention strategies should focus on what they can control. Another important factor is the need for enough, competent nursing staff in the health care sector in order to reach the goals of primary health care in South Africa as set out by the Millennium Development Goals (Pillay, 2010). Consequently, this article proposes the building of strategies around organisational commitment, work engagement and meaning of work amongst nurses.

Nurses have expressed the importance of being valued by their organisation, and being part of a community of practice that gives them a sense of meaning (Hemsley-Brown, 1997). According to Van den Heuvel, Demerouti, Schreurs, Bakker and Schaufeli (2006), it has become progressively important for employees to find meaning and value in their work. Previous research has also acknowledged the importance of the experience of meaning for optimal human functioning (Van den Heuvel et al., 2006). Lack of meaning in one's work may lead to disengagement (Van den Heuvel et al., 2006). Therefore, finding meaning in their work may make nurses feel more energised about their work, and thus more engaged (May, Gilson \& Harter, 2004). Schacklock and Brunetto (2012) found an interesting view on meaning: according to their study, nursing staff are less committed to a specific hospital but seek an environment where they can experience optimal 
meaning in their work. The Towers Perrin Talent Report (2003) states that engagement rests on a meaningful work experience. Organisations must thrive on the mental power of their employees by providing work that leads to employee engagement (Townsend \& Gebhardt, 2008). If employees are engaged they will become aware of the organisational context and will work with others to improve performance within their roles to benefit the organisation (Devi, 2009).

Since people spend more than a third of their lives at work (Wrzesniewski, McCauley, Rozin \& Schwartz, 1997), it is important to look at concepts such as meaning of work and engagement (May et al., 2004). Employees move from one job to another in search of the right company when they don't experience any personal meaning in their work (Singh, Jain \& Bhandarker, 2006).

Organisational commitment can therefore be considered as a fundamental component as it is a result of whether an employee finds meaning in their work (Van den Heuvel et al., 2006). Organisational commitment has been described as the attachment between employees and their organisation (Jacobs \& Roodt, 2007). Employees who are engaged are less likely to leave the organisation due to a concern for and desire to meet patients' needs. Baskin (2007) also found that an employee who is not engaged is more likely to leave the organisation. In a recent global workforce study by the Towers Watson Company (2012), involving 32000 employees across different industries in the world, the link between engagement and retention is confirmed.

It is reported that the number of qualified and unqualified nurses working as nurses has recently shown a significant decline compared with a decade ago (Hemsley-Brown, 1997). The nursing profession has increasingly become vital internationally, and the local shortage of competent nurses could even be referred to as an: 'imminent crisis' (Smyer \& Pitt-Catsouphes, 2007). In South Africa, it has been reported that there are 32000 vacant nursing positions in public hospitals and that most of the employed nurses are over the age of 40 (Pillay, 2009). Brunetto et al. (2013) conclude in their study that the aging population of countries exacerbates the need for nurses, who are already in huge demand. In the current research, it was observed that nurses are working long hours and sacrificing their tea and lunch breaks for the benefit of patients, due to staff shortages. This study will create an understanding of how nurses experience meaning in their jobs and may assist employers to create options for their employees to improve engagement leading to organisational commitment.

The aim of this study was to investigate organisational commitment, engagement and meaning of work amongst nurses in various hospitals. Studies addressing the combination of these topics could not be found in South African research; therefore, this study will add value in the literature, ultimately contributing to an understanding of the relevant issue of the current nursing shortage in this country.

\section{Literature review}

\section{Organisational commitment}

Organisational commitment is described by Meyer and Allen (1991, p. 67), as: 'the emotional attachment to, identification with, and involvement in, the organisation'. Elizur, Kantor, Yaniv and Sagie (1996) note that there are two types of commitment. The first one is moral commitment, which can be described as the attachment or loyalty to something (in this case the hospital), and the second one is calculative commitment, which can be described as the potential benefit a person would gain by being committed.

Porter, Steers, Mowday and Boulian (1974) explain that there are three types of organisational commitment. Affective commitment can be seen as the first domain, which includes the strength of a person's identification with and participation in the organisation. Jernigan, Joyce and Kohut (2002) are of the opinion that individuals possessing affective commitment stay within the organisation, not because they have to or feel obligated to do so, but because they want to stay. Continuance commitment is based on the degree to which the person perceives the costs of leaving the organisation as greater than staying, or simply that the person remains committed because it is their only option (Meyer and Allen, 1991). Jernigan et al. (2002) concur that employees with continuance commitment stay with the organisation because they have to.

Lastly, Steers (1977) explains normative commitment as attaching internalised values to the organisation. It can be regarded as a feeling of obligation towards the organisation (Steers, 1977). Meyer and Allen (1991) identify two mechanisms that can contribute to normative commitment. The first one is a strong correlation between the values of the individual and the values of the organisation. The second mechanism is of a more instrumental nature associated with reward systems. Thus, an employee may be rewarded according to certain criteria, and may then in return feel obligated to stay with the company (Jacobsen, 2000). Therefore, individuals who experience normative commitment, according to Jernigan et al. (2002), are committed to the organisation because they feel it is the right thing to do.

Muthuveloo and Che Rose (2005) assert that it is important to recognise an employee's work perceptions because this could be a direct motivation for the individual and could lead to higher organisational commitment.

These perceptions should be positive in order to improve the motivation of that individual, which could also be an indicator of higher organisational commitment (Muthuveloo \& Che Rose, 2005). Dick and Metcalfe (2001) maintain that there are two dimensions that could affect organisational commitment: individual dimensions and managerial dimensions. According to Dick and Metcalfe, individual dimensions include factors such as age, years in the organisation and internal status within the company. The second factor, managerial, can be described as how the individual is treated within the 
company, which includes factors such as how the individual is supported and developed within the organisation (Dick \& Metcalfe, 2001).

\section{Work engagement}

According to Schaufeli, Salanova, Gonzalez-Roma and Bakker (2002), engagement can be defined as: 'the positive, fulfilling, work-related state of mind that is characterised by vigour, dedication and absorption'. Engagement can also be seen as a state of mind, and is not focused on a specific object, event, individual or behaviour (Saks \& Rothmann, 2006).

Some researchers agree that work engagement not only assists in the decrease of perceived levels of occupational stress (Maslach \& Leiter, 1997; Schaufeli \& Bakker, 2004), but also brings about organisational and financial success through an increase in employee motivation and organisational commitment (Koyuncu, Burke \& Fiksenbaum, 2006; Maslach \& Leiter, 1997). Disengaged employees tend to distance themselves from their work roles and to withdraw cognitively from the current work situation (Koyuncu et al., 2006). Therefore, work engagement is an important factor within any organisation, and more specifically within social service occupations such as nursing (Meyers, 2007; Simpson, 2008), especially since these employees interact with various social systems within the organisation and show the lowest level of work engagement (Cooper \& Burke, 2008).

Saks and Rothmann (2006) state that employees see engagement as a means of repayment toward the organisation. Leiter and Maslach (1998) also explain that engagement can be seen as a constructive indicator of commitment. Thus, nurses can choose on what level or to what degree they want to be engaged in their work, which, in turn, influences their loyalty and commitment to the organisation (Blizzard, 2002).

Blizzard (2002) declares that engaged employees are loyal and psychologically committed to the organisation. This view was also confirmed by Jordaan and Rothmann (2005). Therefore, a higher level of work engagement benefits the employer in that it has an impact on the competitive advantage of the organisation (Bakker, Schaufeli, Leiter \& Taris, 2008).

According to the Towers Perrin Talent Report (2003), work engagement is seen as involving both emotional and rational factors relating to work and the overall work experience. Emotional factors are those leading to a sense of personal satisfaction, and the inspiration and affirmation received from the work and being part of the organisation. This could come from having a strong sense of personal accomplishment in the job they perform. It can therefore be concluded that engagement is related to meaningful work (Maslach \& Leiter, 1997).

\section{Meaning of work}

In an integration of historical views on the meaning of work, Bellah, Madsen, Sullivan, Swidler and Tipton (1985, p. 81) defined it as the: 'degree of general importance that the subjective experience of working has in the life of an individual, at any given time'. According to Bellah et al. (1985) these subjective experiences can be classified into three main categories: the individual experiences work as a job, a career or a calling.

According to Wrzesniewski et al. (1997), individuals who view their work as a job are engaged in their work only for the material benefits they receive from it. Therefore, these individuals perceive work to be nothing more than a means to a financial end (Bellah et al., 1985; Parry, 2006). In contrast, individuals who view their work as a career are concerned with the progression of continuous advancement within the organisation (Bellah et al., 1985; Parry, 2006; Wrzesniewski et al., 1997), through dedicating considerable amounts of time and energy to work-related activities for future gain (Wrzesniewski et al., 1997). Viewing work as a calling implies the feeling that one was placed on earth to engage in these specific work-related tasks (Parry, 2006). People in this category obtain a sense of fulfilment from those activities (Wrzesniewski et al., 1997). Lok and Crawford (2001) have found that age also plays a role in the meaning employees derive from their work and the level of their commitment.

Another interesting factor is the increase in the numbers of nursing managers becoming separated from their nursing origins (Allen, 2000; Carpenter, 1977). This is due to the restructuring of the health care system, in which nursing managers are moved further away from the clinical setting (Clifford, 1998; Rankin \& Campbell, 2006). These changes within organisations may pose a threat to the meaning that individuals experience in their work. As a result of such organisational change individuals may experience disengagement (Burger, Crous \& Roodt, 2013). This is problematic as good nursing managers are able to ease the negative impacts of change on nurses within the hospital (Cummings, Hayduk \& Estabrooks, 2005). These nursing managers might experience their work as a career rather than a calling. The support provided by nurse managers is essential to a healthy and productive work environment (Kramer et al., 2007). Nurses remain the largest group of professional employees in the health care system.

In previous research it was confirmed that the calling orientation might be attributed to people knowing that they have an impact on others' lives (Van Zyl, Deacon \& Rothman, 2010). Since the nursing profession has a strong impact on the lives of others, nurses might also perceive their work more as a calling as found in the research of both Bellah et al. (1985) and Van Zyl et al. (2010). For this reason, what nurses do, why they do what they do and how well they do it, are significant factors that directly affect the quality of care the patient receives, and hospitals should constantly work towards sustaining such quality (Her Majesty's Stationery Office, 1979). Burger et al. (2013) are of the opinion that meaning in work should be considered a critical variable in framing change initiatives for organisations to succeed. Therefore, aspects such as organisational commitment, 
work engagement and meaning of work should be studied. According to Van Zyl et al. (2010), the understanding of the effect of these aspects on employees can lead to a deeper level of understanding of the happiness of employees. Therefore, people who are emotionally, cognitively and physically involved in their work may experience work engagement. Van Zyl et al. (2010) state that organisations need to realise that employees who experience meaning within their work may in the long term be instrumental in organisational success.

In the literature study, the constructs of organisational commitment, work engagement and meaning of work are defined and the relationship between them described. Figure 1 proposes a conceptual model of the relationships between these constructs, which was used in this study.

Based on the above problem statement and literature review, the following hypotheses are formulated:

- Hypothesis 1: A practically significant relationship exists between meaning of work (job, career or calling) and organisational commitment.

- Hypothesis 2: A practically significant relationship exists between meaning of work (job, career or calling) and work engagement.

- Hypothesis 3: Meaning of work as a calling predicts work engagement.

- Hypothesis 4: Meaning of work as a calling predicts commitment.

\section{Research design \\ Research approach}

The researcher made use of a quantitative research design, which can be defined, according to De Vos, Strydom, Fouche and Delport (2007), as an investigation into a social or human problem, based on testing a theory composed of variables. This is measured with numbers and analysed with statistical procedures in order to establish whether the prognostic generalisations of the theory hold true. The

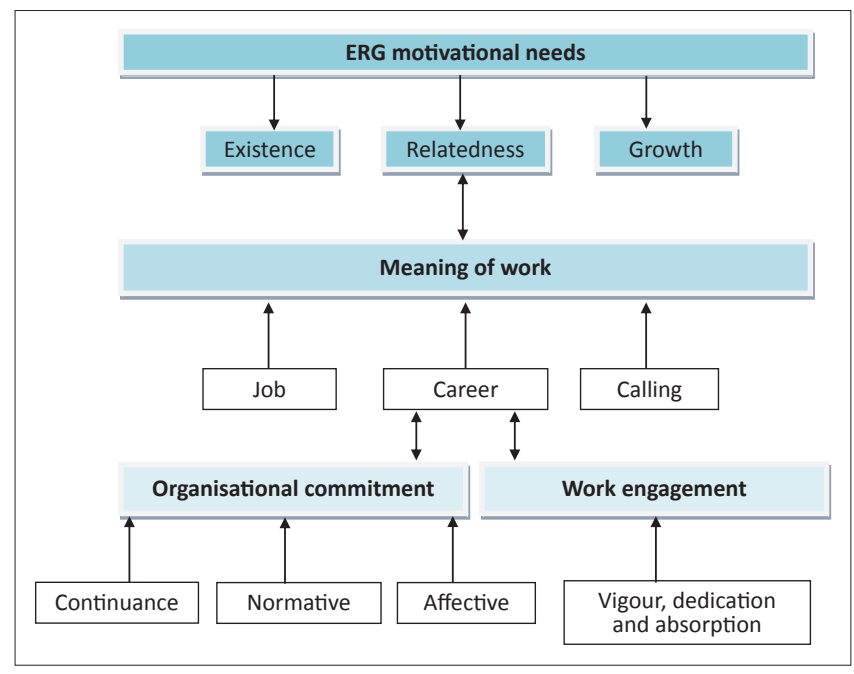

Source: Based on Clayton Aldefer theory, and adapted from: Robbins, S.P., Odendaal, A., \& Roodt, G. (2003). Organisational behaviour. Cape Town, South Africa: Pearson Education.

FIGURE 1: The motivation process. research can be classified as descriptive and cross-sectional. Descriptive research presents a picture of the specific details of a situation, social setting or relationship and focuses on 'how' and 'why' questions (De Vos et al., 2007). Welman and Kruger (2001) describe a cross-sectional design as a research design in which subjects are assessed at a single time in their lives. A cross-sectional study is fast and can study a large number of respondents with little cost or effort. De Vos et al. refer to this kind of design as a one-shot case study: a group is studied only once.

\section{Research method}

\section{Participants}

A cluster sample $(n=199)$ of both permanent and nonpermanent nurses at private hospitals was selected. In this sampling method the researcher divides the participants in the hospital into groups and then selects any of those numbers of groups at random. Next, the characteristics of the study population will be described.

The study population consisted of $96.5 \%$ female participants and $2.5 \%$ male participants. Furthermore, the sample comprised Black (34.2\%), White (63.8\%) and Indian (2.0\%) participants (none was mixed-race), of whom 10.6\% were managers, $6.1 \%$ were senior sisters, $33.5 \%$ sisters, $19.3 \%$ staff nurses, $7.6 \%$ assistant nurses, $19.3 \%$ student nurses and $3.6 \%$ other types. The majority of the participants were registered nurses. The ages of the participants were 35 years and younger $(33.9 \%), 36-45$ years $(30.4 \%)$, or 46 years and older (35.7\%). Most participants had from two to five years' experience $(31.6 \%)$, and most indicated a diploma as their level of qualification $(42.9 \%)$. The majority of nurses were permanently employed $(72.4 \%) ; 27.6 \%$ were employed on a contract basis.

\section{Measuring instruments}

The following measuring instruments were used for the purpose of empirical study.

Organisational Commitment Questionnaire (OCQ): According to Meyer and Allen (1991), this measure views organisational commitment from three perspectives: affective, continuance and normative commitment. Affective commitment refers to employees' degree of emotional attachment to and identification with the organisation. The continuance component refers to the level of commitment that employees associate with the organisation based on the perceived costs of leaving the organisation. Thirdly, the normative component refers to the employee's feeling that they have a responsibility to remain within the organisation and not leave it for another one. The 18 items are measured on a five-point Likert-type scale ranging from 1 (strongly disagree) to 5 (strongly agree), which includes items such as: 'I would be very happy to spend the rest of my career in this organisation', 'I do not feel any obligation to remain with my current employer' and 'Right now, staying with my organisation is a matter of necessity as much as desire'. High scores on the affective commitment scale (ACS), normative 
commitment scale (NCS) and continuance commitment scale (CCS) are an indication of organisational commitment. Research conducted by Meyer and Allen indicates that the reliability figures for the three scales of commitment by means of coefficient alpha values are above the acceptable levels and are as follows: ACS 0.87, CCS 0.75 and NCS 0.79 .

The Utrecht Work Engagement Scale (UWES): The scale developed by Schaufeli et al. (2002) was utilised as a measure of work engagement amongst nurses at hospitals. This 17item questionnaire is measured on a seven-point frequency scale, ranging from 0 (never) to 6 (always); the measure has three sub-scales: vigour, dedication and absorption. Example items are, 'I feel strong and vigorous in my job', 'I always persevere at work, even when things do not go well' and 'In my job, I can continue working for very long periods at a time'. Regarding internal consistency, Cronbach's alpha coefficients have been determined at between 0.68 and 0.91 (Schaufeli et al., 2002). In a study amongst South African workers, Olivier and Rothmann (2007) obtained an alpha coefficient of 0.72 , implying that the instrument is reliable in the South African context.

The Work-Life Questionnaire (WLQ): This questionnaire was developed by Wrzesniewski et al. (1997) and aims to measure an individual's orientation to work (meaning of work). These orientations are classified into three main categories: work as a job, work as a career and work as a calling. The questionnaire is divided into two parts. The first part contains three paragraphs signifying the three work orientations and is a self-report measure. Participants have to read all three paragraphs and then rate their level of association with each paragraph as: 'very much me', 'somewhat', 'a little', or 'not at all like me'. The second part consists of 18 true or false items about specific aspects of relation to work that are relevant to the three work orientations in the first part of the questionnaire. A typical item is: 'My primary reason for working is financial'.

In previous research, that included nurses in the sample, Wrzesniewski et al. (1997) found the reliability of this instrument to be adequate. Van Zyl et al. (2010) reported Cronbach's alpha coefficients ranging between 0.87 and 0.80 for the WLQ in a South African study. The results of this questionnaire provide an indication of where the respondent falls on the job-career-calling continuum.

\section{Research procedure}

Ethics approval was obtained by the ethics committee of the participating university. The researcher requested permission from hospital management to conduct the research. In each ward a meeting was scheduled with the matron to discuss how the questionnaires would be distributed, completed and collected with the least interruption of duties. The researcher took the questionnaires to each ward at the arranged time and waited for participants to complete them. Information was provided on the reason and focus of the study. Anonymity was ensured and participants could withdraw at any stage.

\section{Statistical analysis}

The SPSS program was used to carry out the statistical analysis. Descriptive statistics (i.e. means, standard deviations, skewness and kurtosis) were used to analyse the data. Exploratory factor analysis was conducted and Cronbach's alpha $(\alpha)$ coefficients and inter-item correlation coefficients calculated and used to determine the validity and reliability of the measuring instruments. Depending on the distribution of the data, either a Pearson product-momentum correlation or Spearman correlation coefficients was used to specify the relationships between the variables. A $p$-value smaller than or equal to 0.01 was used for statistical significance. A cutoff point of 0.30 (medium effect) was set for the practical significance of correlation coefficients (Cohen, 1992).

Multiple regression analyses were carried out to determine the percentage variance in the dependent variables that was predicted by the independent variables.

\section{Results}

Factor analysis was carried out to investigate the underlying factor structure of the measuring instruments. Firstly, principal component analysis was used to assess the factorability of the items of the various scales, and to determine the number of factors in each scale; eigenvalues $(>1)$ and the scree plot were used to determine the number of factors in each scale. Secondly, a principal axis factor analysis with a direct oblimin rotation was used in cases where scales had more than two factors.

A principal component analysis was conducted on the 24 items of the OCQ. The Kaiser-Meyer-Olkin measure of sampling adequacy revealed a value of 0.79 , which indicates that the items were factorable (Field, 2006). Bartlett's test of sphericity was shown to be highly significant at 276.00 . The scale produced communalities that were all higher than the suggested 0.30. A principal component analysis showed that eight factors could be extracted, all of which were higher than 1. They represented $64.13 \%$ of the total variance explained. Further analysis was done using the Total Commitment Scale.

A principal component analysis was conducted on the 17 items of the UWES. The Kaiser-Meyer-Olkin measure of sampling adequacy showed a value of 0.92 , which indicates that the items were well above the suggested 0.60 (Field, 2006). Bartlett's test of sphericity was found to be highly significant at 136.00. The scale produced communalities that were all higher than the suggested 0.30 .

The principal component analysis showed that two factors (with eigenvalues of 9.13 and 1.07) could be extracted that were larger than 1 and this was confirmed by the scree plot which also showed two factors. These components explain in total $60 \%$ of the variance of the instrument. A one-factor structure was used in further analysis because the original three-factor structure was not found. 
At first, a direct oblimin rotation was used. However, because the inter-item correlation did not show sufficient correlation, the varimax rotated factor analysis was used on the WLQ and three factors were specified. All items loaded onto factor 1 (calling) factor 2 (career) or factor 3 (job). Two items did not load on any factors and were deleted. The Kaiser-MeyerOlkin measure of sampling adequacy showed a value of 0.79 , which indicates that the items were factorable. Bartlett's test of sphericity was shown to be highly significant $\left(\chi^{2}(210)=\right.$ 885.05; $p<0.05)$. Communalities for the scale were produced, all showing higher than the suggested 0.30 . The principal axis factoring showed that three factors (with eigenvalues of 5.22, 2.30 and 1.66 respectively) could be extracted. They represented $63.75 \%$ of the total variance explained.

\section{Descriptive statistics}

The descriptive statistics (mean, standard deviations and Cronbach's alpha coefficients) of the measuring instruments are reported in Table 1.

Inspection of Table 1 shows that acceptable Cronbach's alpha coefficients were obtained for most of the scales. All of the alpha coefficients were higher than the guideline of $\alpha>0.70$ (Nunnally, 1978), except for the MOW-Job and MOW-Career subscales of the WLQ. Furthermore, the scores on all scales were normally distributed, as indicated by their skewness and kurtosis. It therefore appears that the measuring instruments had acceptable levels of internal consistency, although engagement has a slight skewness of -1.01 and the work-life calling construct a kurtosis of -1.03 . The mean scores of the meaning of work orientations, calling and job, varied by only 0.51 , indicating, therefore, that the majority of nurses view their work as either a job (18.81) or a calling (18.30).

Next, Pearson product-moment correlations were done as reported in Table 2 .

Table 2 shows the following statistically and practically significant correlations: the MOW-Calling and MOW-Job

TABLE 1: Descriptive statistics and Cronbach's alpha coefficients of the measuring instruments.

\begin{tabular}{llllll}
\hline Tests and subscales & $\mathbf{M}$ & SD & Skewness & Kurtosis & $\boldsymbol{\alpha}$ \\
\hline 1. Commitment & 76.92 & 12.72 & -0.42 & 0.01 & 0.82 \\
2. Engagement & 72.25 & 19.71 & -1.01 & 0.49 & 0.94 \\
3. MOW - Job & 18.81 & 4.30 & -0.42 & -0.17 & 0.62 \\
4. MOW - Career & 7.82 & 2.60 & 0.35 & -0.77 & 0.63 \\
5. MOW - Calling & 18.30 & 5.74 & 0.19 & -1.03 & 0.84 \\
\hline
\end{tabular}

MOW, commitment, engagement; M, mean; SD, standard deviation; $\alpha$, alpha.

TABLE 2: Comparison of correlation coefficients between organisational commitment, work engagement and meaning of work amongst nurses $(n=199)$.

\begin{tabular}{lllll}
\hline Tests and subscales & $\mathbf{1}$ & $\mathbf{2}$ & $\mathbf{3}$ & $\mathbf{4}$ \\
\hline 1. MOW-Job & 1.00 & - & - & - \\
2. MOW-Career & -0.11 & 1.00 & - & - \\
3. MOW-Calling & $-0.50^{* \mathrm{~b}}$ & $0.18^{*}$ & 1.00 & - \\
4. Commitment & $0.38^{* \mathrm{a}}$ & -0.11 & $-0.47^{* \mathrm{a}}$ & 1.00 \\
5. Engagement & $0.54^{* \mathrm{~b}}$ & -0.10 & $-0.57^{* \mathrm{~b}}$ & $0.42^{* \mathrm{a}}$ \\
\hline
\end{tabular}

MOW, commitment and engagement.

a, Correlations are practically significant, $r \geq 0.30$ (medium effect).

, Correlations are practically significant, $r \geq 0.50$ (large effect).

*, Statistically significant at $p \leq 0.01$ correlated negatively statistically and practically significantly $(r=0.50 ; p<0.01 ;$ large effect). This indicates that people experience meaning of work as either a job or a calling on a continuous scale, which was confirmed in previous research by Wrzesniewski et al. (1997). Furthermore, Organisational Commitment and MOW-Job had a positive statistically and practically significant correlation $(r=0.38 ; p<0.01$; medium effect). It should be noted that the fact that the scale on the WLQ was reversed means that people viewing their work as a job are less committed or that less committed people tend to view their work as a job. MOW-Calling and Organisational Commitment had a statistically negative correlation, with a practically significant negative correlation with a medium effect $(r=-0.47 ; p<0.01)$; again, it should be remembered that the WLQ items were reversed. Therefore, the stronger an individual's view of their work as a calling, the more committed they will be to the organisation. Based on the above analysis, Hypothesis 1, 'A practically significant relationship exists between meaning of work (job, career or calling) and organisational commitment', can be accepted.

Work engagement and MOW-Job had a statistically and practically significant positive correlation $(r=0.54 ; p<0.01$; large effect). The more people view their work as a job the less engaged they will be, because the scale on the WLQ was reversed. MOW-Calling and work engagement had a statistically and practically significant negative correlation $(r=-0.57 ; p<0.01$; large effect); therefore, the stronger a person's view of their work as a calling, the more engaged they will be in their work. Based on the above analysis, Hypothesis 2, 'A practically significant relationship exists between meaning of work (job, career or calling) and work engagement', can be accepted.

Lastly, work engagement and organisational commitment had a statistically and practically significant positive correlation $(r=0.42 ; p<0.01$; medium effect). Those who are engaged in their work will be more committed to the organisation, or if they are more committed they will be more engaged.

Next, a multiple regression analysis was conducted to test whether meaning of work predicts organisational commitment and work engagement. Step 1 was used to control for the influence that meaning of work (calling) has on the dependent variable work engagement and step 2, career, was included to control for the influence on work engagement as the dependent variable. Step 3, job, was included as the independent variable.

Table 3 indicates that $30 \%$ of the variance in work engagement is predicted by the meaning of work variable calling $(F=58.81$; $p<0.00)$. When career was added it made no significant contribution to the variance explained. Adding job $(F=28.53$; $p<0.00)$ in step 3 increased the $R^{2}$, explaining 39\% of the variance in work engagement. The meaning of work variable job, therefore, predicted $9 \%$ of the variance in work engagement and calling predicted $30 \%$. Based on the above analysis, Hypothesis 3, 'Meaning of work as a calling predicts work engagement', can be accepted. 
Next, a series of multiple regression analyses were performed to test whether meaning of work (calling, career or job) predicts organisational commitment. Firstly, the previous results have already shown that being engaged in one's work is predicted by whether one views one's work as a calling or a job. Secondly, to test whether organisational commitment is predicted by meaning of work, a multiple regression analysis was carried out with organisational commitment as the dependent variable and meaning of work (calling, career or job) as the independent variable. Step 1 was used to control for the influence that meaning of work (calling) has on the dependent variable organisational commitment and step 2, to control for the influence of meaning of work (career) on organisational commitment as the dependent variable. Step 3 included meaning of work (job) to control for the influence on organisational commitment.

Table 4 shows that meaning of work (calling) predicts 19\% of the variance in organisational commitment $(F=32.50 ; p$ $<0.00)$. When career was added it also made no significant contribution to the variance explained. It also showed that when job was added in step 3 it increased the $\mathrm{R}^{2}$, explaining $23 \%$ of the variance in organisational commitment $(F=13.66$; $p<0.00)$. The meaning of work variable, job, therefore predicted $4 \%$ of the variance in organisational commitment and calling predicted $19 \%$. It can be concluded that calling predicts organisational commitment. Therefore, based on the above analysis, Hypothesis 4, 'Meaning of work as a calling predicts commitment', can be accepted.

\section{Discussion}

The aim of this study was to establish the relationship between organisational commitment, work engagement and meaning of work amongst nurses in hospitals. The factor analysis and Cronbach's alpha coefficient calculations were conducted by means of statistical calculations. Exploratory factor analysis showed an eight-factor model for organisational commitment, which is not in line with the literature. Furthermore, a threefactor model was extracted for meaning of work and a twofactor model for work engagement. The descriptive statistics indicated that the scales of the OCQ, UWES and WLQ were sufficiently internally consistent with accepted alpha values for most of the scales. This implies that the survey used was reliable in the sample of nurses. The results showed that the sample was made up mainly of registered female nurses and that the majority viewed their work as either a job or a calling. Nursing is viewed as a stable job with opportunities of employment, which is desirable in a world with few job opportunities. On the other hand people who feel they want to contribute and aid those in need of health care, find nursing a calling.

TABLE 3: Regression analyses with meaning of work (job, career or calling) as the independent variable and work engagement as the dependent variable.

\begin{tabular}{|c|c|c|c|c|c|c|c|c|c|}
\hline \multirow[t]{2}{*}{ Model and/or variable } & \multicolumn{2}{|c|}{ Unstandardised coefficients } & \multirow{2}{*}{$\begin{array}{c}\text { Standardised } \\
\text { coefficients (Beta) }\end{array}$} & \multirow[t]{2}{*}{$t$} & \multirow[t]{2}{*}{$p$} & \multirow[t]{2}{*}{$F$} & \multirow[t]{2}{*}{$R$} & \multirow[t]{2}{*}{$R^{2}$} & \multirow[t]{2}{*}{$\Delta R^{2}$} \\
\hline & B & SE & & & & & & & \\
\hline Model 1 & - & - & - & - & - & 58.81 & 0.55 & 0.30 & 0.30 \\
\hline 1. (Constant) & 106.15 & 4.67 & - & 22.73 & $0.00 *$ & & & & \\
\hline Total calling & -1.86 & 0.24 & -0.55 & -7.67 & $0.00 *$ & & & & \\
\hline Model 2 & - & - & - & - & - & 29.43 & 0.55 & 0.30 & 0.00 \\
\hline 2. (Constant) & 108.35 & 6.03 & - & 17.97 & $0.00 *$ & - & - & - & - \\
\hline Total calling & -1.84 & 0.25 & -0.54 & -7.47 & $0.00 *$ & - & - & - & - \\
\hline Total career & -0.32 & 0.56 & -0.04 & -0.58 & 0.56 & - & - & - & - \\
\hline Model 3 & - & - & - & - & - & 28.53 & 0.62 & 0.39 & 0.10 \\
\hline 3. (Constant) & 69.25 & 10.60 & - & 6.53 & $0.00 *$ & - & - & - & - \\
\hline Total calling & -1.21 & 0.27 & -0.36 & -4.47 & $0.00 *$ & - & - & - & - \\
\hline Total career & -0.19 & 0.52 & -0.02 & -0.36 & 0.72 & - & - & - & - \\
\hline Total job & 1.91 & 0.44 & 0.35 & 4.36 & $0.00 *$ & - & - & - & - \\
\hline
\end{tabular}

B, regression coefficient; $\mathrm{SE}$, standard error; $t$,obtained $t$-test value; $F, F$-value; $R$, multiple correlation; $R^{2}$, proportion variance explained.

$*, p<0.01$ (Statistically significant difference)

TABLE 4: Regression analyses with meaning of work (job, career or calling) as the independent variable and organisational commitment as the dependent variable.

\begin{tabular}{|c|c|c|c|c|c|c|c|c|c|}
\hline \multirow[t]{2}{*}{ Model and/or variable } & \multicolumn{2}{|c|}{ Unstandardised coefficients } & \multirow{2}{*}{$\begin{array}{c}\text { Standardised } \\
\text { coefficients (Beta) }\end{array}$} & \multirow[t]{2}{*}{$t$} & \multirow[t]{2}{*}{$\bar{p}$} & \multirow[t]{2}{*}{$F$} & \multirow[t]{2}{*}{$R$} & \multirow[t]{2}{*}{$R^{2}$} & \multirow[t]{2}{*}{$\overline{\Delta R^{2}}$} \\
\hline & B & SE & & & & & & & \\
\hline Model 1 & - & - & - & - & - & 32.50 & 0.44 & 0.19 & 0.19 \\
\hline 1. (Constant) & 74.25 & 2.71 & - & 27.43 & $0.00 *$ & - & - & - & - \\
\hline Total calling & -0.81 & 0.14 & -0.44 & -5.70 & $0.00 *$ & - & - & - & - \\
\hline Model 2 & - & - & - & - & - & 16.75 & 0.44 & 0.20 & 0.01 \\
\hline 2. (Constant) & 76.26 & 3.38 & - & 22.58 & $0.00 *$ & - & - & - & - \\
\hline Total career & -0.31 & 0.31 & -0.08 & -1.00 & 0.32 & - & - & - & - \\
\hline Model 3 & - & - & - & - & - & 13.66 & 0.48 & 0.23 & 0.04 \\
\hline 3.(Constant) & 63.63 & 6.06 & - & 10.51 & $0.00^{*}$ & - & - & - & - \\
\hline Total calling & -0.59 & 0.16 & -0.32 & -3.63 & $0.00 *$ & - & - & - & - \\
\hline Total career & -0.31 & 0.31 & -0.08 & -1.00 & 0.32 & - & - & - & - \\
\hline Total job & 0.65 & 0.26 & 0.22 & 2.49 & $0.01^{*}$ & - & - & - & - \\
\hline
\end{tabular}

$\mathrm{B}$, regression coefficient; $\mathrm{SE}$, standard error; $t$, obtained $t$-test value; $F, F$-value; $R$, multiple correlation; $R^{2}$, proportion variance explained.

${ }^{*}, p<0.01$ (Statistically significant difference) 
The Pearson correlations in this study indicated that the calling orientation towards work correlated negatively with the job orientation. Therefore, nurses who view their work as a calling are not influenced much by financial gain; they are in the profession as they feel that they were born to do it.

Calling also correlated positively with work engagement and organisational commitment, demonstrating that the more that nurses view their work to be a calling, the more likely they are to be engaged in their work and the more committed they are to the organisation. $\mathrm{Wu}$ (2010) also found that engaged nurses experienced meaning in their work.

Lastly, organisational commitment and work engagement had a positive correlation (as the one increases, so will the other). This indicates that the more committed nurses are to the organisation, the more engaged they will be in their work or, similarly, the more engaged they are, the more committed they will be. Career and calling orientations had a slightly positive correlation with each other, indicating that nurses who view their work as a calling might want to achieve a higher level of employment within the organisation.

The second set of regression analyses indicated that the meaning of work variable, calling, predicts both work engagement and organisational commitment; this is a positive relationship. Therefore, nurses viewing their work as a calling will be more engaged in their work and more committed to the organisation than nurses viewing their work as a job.

In conclusion, based on the results of this study, it is evident that many nurses view their work as a calling, whilst some view their work as a job. Nurses who view their work as a calling are more committed to the organisation and more engaged in their work.

\section{Practical implications: Recommendations for hospitals}

Hospitals that want to be market leaders need to recognise the importance of focusing on nurses' organisational commitment and work engagement for the benefit of both the organisation and its employees. The following are recommended to hospitals:

- The knowledge gained from this study's results and the theoretical knowledge gained from literature could be incorporated into the effective nursing criteria in the screening and selection of appropriate participants for the future. Muthuveloo and Che Rose (2005) state that it is important to recognise an employee's work perceptions, which can be a direct motivation for the individual, which would in return lead to higher organisational commitment.

- Regular staff feedback sessions or focus groups should be implemented, in which nurses have the opportunity to share their insights with regard to how processes may be improved, to share inspiring stories about patients they may have encountered and treated, and so on. By doing so the hospital establishes a sense of organisational support and enhances nurses' self-fulfilment they receive from hearing and sharing.

- Hospitals should consider implementing community projects, where nurses willingly provide their services pro bono in order to help out patients who do not have the financial capacity to afford such services. By doing so nurses give something back to the community and in turn realise the difference they make in people's lives; this will also enhance the feeling of finding meaning in their work.

- Most of the nurses in the hospitals are 46 years and older; therefore, hospitals should realise the risks and opportunities of an aging workforce and implement recruitment strategies accordingly. It is important that older workers be retained to optimise transfer of learning to younger, inexperienced workers.

- Considering the nurse shortage in South Africa, crafting job options that are consistent with the preferences of employees of different age groups is an important employer strategy. It is important to ensure smooth flow of talent management to ensure vacancies are filled quickly, thus avoiding unnecessary demands on current staff.

- Hospitals should implement bursary programmes to provide support to staff members, in order to further their careers. The information obtained in this study showed that career correlated positively with calling; therefore, viewing your work as either a calling or a career enhances organisation commitment and work engagement.

- Outreach programmes to universities may be looked at, in which current nurses give motivations and explanations regarding their occupation to motivate young people to follow in their footsteps. This will raise awareness about the occupation and in turn bring more people into the profession. Talent can be identified and bursaries offered; bursary holders who have agreed and been selected could then work for the hospital for a set period after studies have finished.

\section{Limitations of the study}

The following limitations have been noted with regard to the study:

- A cross-sectional research design was used and the respondents were only assessed once; this limits the determination of cause-and-effect relationships. Participants were also only assessed at a single time in their lives.

- A cluster sample was used as the sampling method of permanent and non-permanent nurses in hospitals. However, only 199 questionnaires were returned. Although a larger sample would have been more beneficial, the sample size of 199 is reasonable and large enough to generalise findings to the larger population.

- The measures that were administered were in English; this could be a limitation due to a potential language barrier for participants whose first language was not English. Translation into other languages could have resulted in better feedback. 
- The use of self-report measures could be a limitation as it tests the participants' perceptions about the constructs and might not measure the constructs themselves.

- The test battery itself was lengthy and this may have caused participants to give a convenient answer instead of the needed consideration.

\section{Recommendations for future research}

The following recommendations resulting from the study can be made for future research:

- Longitudinal studies need to be utilised in order to determine the causal factors and relationships between organisational commitment, work engagement and meaning of work.

- The sample size of 199 should be expanded to a larger sample size to enhance external validity and the involvement of both government and private hospitals could be obtained to see differences in environment.

- To enhance cultural appropriateness, equivalence studies can be conducted and the questionnaire could be translated into other applicable languages.

\section{Conclusion}

As would be expected, organisational commitment and work engagement had a positive correlation. Calling predicted a significant variance in both organisational commitment and work engagement. Nursing staff view their work more as a calling, which implies higher levels of commitment and engagement. The result indicates that even with the pressures and challenges in the nursing profession, nurses can still be committed and engaged. Hospitals could gain an advantage by focusing on interventions to enhance the experience of work as a calling.

\section{Acknowledgements Competing interest}

The authors declare that they have no financial or personal relationship(s) that may have inappropriately influenced them in writing this article.

\section{Authors' contribution}

I.B. (North-West University) did the literature review and empirical study as part of her master's dissertation. She collected all the data whilst the statistical analysis was performed by E.B. (North-West University), who was also the supervisor of this study.

\section{References}

Allen, D. (2000). Doing occupational demarcation: The 'boundary work' of nurse managers in a district general hospital. Journal of Contemporary Ethnography, 29(3), 326-56. http://dx.doi.org/10.1177/089124100129023936

Bakker, A., Schaufeli, W.B., Leiter, M.P., \& Taris, T.W. (2008). Work engagement: An emerging concept in occupational health psychology. Work \& Stress, 22, 187-200. http://dx.doi.org/10.1080/02678370802393649

Baskin, B. (2007, November). Vigor, dedication, and absorption: work engagement among secondary English teachers in Indonesia. Paper presented at the annual AARE Conference, Fremantle, Perth, Australia.
Bellah, R., Madsen, R., Sullivan, W., Swidler, A., \& Tipton, S. (1985). Habits of the Heart: Individualism and commitment in American life. California: University of California Press.

Blizzard, D.B.A. (2002). Nurses may be satisfied, but are they engaged? Retrieved October 10, 2009, from http://www.gallup.com/poll/tb/healthcare/20020514.9 $5 p$ ?Version=pp

Brunetto, Y., Xerri, M., Shriberg, A., Farr-Wharton, R., Schacklock, K., Newman, S. et al. (2013). The impact of workplace relationships on engagement, well-being commitment and turnover for nurses in Australia and the USA. Journal of Advanced Nursing, May. http://dx.doi.org/10.1111/jan.12165

Burger, D.H., Crous, F., \& Roodt, G. (2013). Exploring a model for finding meaning in the changing world of work (Part 3: Meaning as framing context). SA Journal of Industrial Psychology/SA Tydskrif vir Bedryfsielkunde, 39(2), Art. \#1022, 10 pages. http://dx.doi.org/10.4102/sajip.v39i2.1022

Carpenter, M. (1977). The new managerialism and professionalism in nursing. In M. Stacey, M. Reid, C. Heath, \& R. Dingwall (Eds.). Health and the Division of Labour (pp. 165-193). London, UK: Croom Helm.

Clifford, J.C. (1998). Restructuring: The Impact of Hospital Organization on Nursing Leadership. Chicago, IL: American Hospital Publishing.

Cohen, A. (1992). Antecedents of organizational commitment across occupational groups: A meta-analysis. Journal of Organizational Behavior, 13, 539-558. http:// groups: A meta-analysis. Journal of Orga
dx.doi.org/10.1002/job.4030130602

Cooper, C., \& Burke, R. (2008). The Peak Performing Organization. London, UK: Routledge.

Cummings, G., Hayduk, L., \& Estabrooks, C. (2005). Mitigating the impact of hospital restructuring on nurses: the responsibility of emotionally intelligent leadership. Nursing Research, 54(1), 2-12. http://dx.doi.org/10.1097/00006199-20050100000002, PMid:15695934

De Vos, A.S., Strydom, H., Fouche, C.B., \& Delport, C.S.L. (2007). Research at grass roots for the social sciences and human service professions. (3rd edn.). Pretoria, South Africa: Van Schaik Publishers.

Devi, V.R. (2009). Employee engagement is a two way street. Human Resource Management International Digest, 17, 3-4. http://dx.doi.org/10.1108/09670730910940186

Dick, G., \& Metcalfe, B. (2001). Managerial factors and organisational commitment. The International Journal of Public Sector Management, 14, 111-128. http://dx.doi. org/10.1108/09513550110387336

Elizur, D., Kantor, J., Yaniv, E., \& Sagie, A. (1996). Importance of life domains in different cultural groups. American Journal of Psychology, 121(1), 35-46. http://dx.doi. org $/ 10.2307 / 20445442$

Field, A. (2006). Discovering Statistics Using SPSS. (2nd edn.). London, UK: Sage Publications Ltd.

Hemsley-Brown, J. (1997). Counting nurses: Interpreting nursing workforce statistics. Health Manpower Management, 23(5), 159-166. http://dx.doi.org/10.1108/ 09552069710175445

Her Majesty's Stationery Office (HMSO). (1979). Royal Commission on the National Health Service. London, UK.

Jacobs, E., \& Roodt, G. (2007). The development of a knowledge sharing construct to predict turnover intentions. Research Paper, 59(3), 229-248.

Jacobsen, D.I. (2000). Managing increased part-time: does part-time work imply parttime commitment? Managing Service Quality, 10(3), 187-201. http://dx.doi. org/10.1108/09604520010336713

Jernigan, I.E., Joyce, M.B. \& Kohut, G.F. (2002). Dimensions of work satisfaction as predictors of commitment type. Journal of Managerial Psychology, 17(7), 564-579.

Jordaan, G.M.E., \& Rothmann, S. (2005). Work engagement of academic staff in South African higher institutions. Potchefstroom, South Africa: WorkWell Research Unit for People, Policy and Performance, North-West University. PMCid:PMC1831920

Koyuncu, M., Burke, R.J., \& Fiksenbaum, L. (2006). Work engagement among women managers and professionals in a Turkish bank: potential antecedents and
consequences. Equal Opportunities International, 25, 299-310. http://dx.doi. consequences. Equal Opportunities
org/10.1108/02610150610706276

Kramer, M., Maquire, P., Brewer, B., Chmielewski, L., Kishner, J., Krugman, M. et al. (2007). Nurse manager support: what is it? Structures and practices that promote it. Nursing Administration Quarterly, 31(4), 325-40. http://dx.doi.org/10.1097/01. it. Nursing Administration Q

Leiter, M. P., \& Maslach, C. (1998). The impact of interpersonal environment on burnout and commitment. Journal of Organisational Behavior, 9, 297-308. http:// dx.doi.org/10.1002/job.4030090402

Lok, P., \& Crawford, J. (2001). Antecedents of organisational commitment and the mediating role of job satisfaction. Journal of Managerial Psychology, 16(8), 594613. http://dx.doi.org/10.1108/EUM0000000006302

Maslach, C., \& Leiter, M.P. (1997). The truth about burnout. San Francisco, CA: JosseyBass. PMid:9332965

May, D., Gilson, R., \& Harter, L. (2004). The psychological conditions of meaningfulness, safety and availability and the engagement of the human spirit at work. Journal
of Occupational and Organizational Psychology, 77, 11-37. http://dx.doi.org/ of Occupational and Organization
$10.1348 / 096317904322915892$

Meyer, J.P., \& Allen, N.J. (1991). A three-component conceptualization of organisational commitment. Human Resource Management Review, 1, 61-98. http://dx.doi. commitment. Human Resource Mand
org/10.1016/1053-4822(91)90011-Z

Meyers, C. (2007). Industrial Psychology. New York, NY: Garnsey Press.

Muthuveloo, R., \& Che Rose, R. (2005). Typology of organisational commitment. American Journal of Applied Science, 2(6), 1078-1081. http://dx.doi.org/10.3844/ ajassp.2005.1078.1081

Nunnally, C. (1978). Psychometric theory. (2nd edn.). New York, NY: McGraw-Hill. 
Olivier, A.L. \& Rothmann, S. (2007). Antecedents of work engagement in a multinational oil company. SA Journal of Industrial Psychology, 33(3), 49-56. http://dx.doi. org/10.4102/sajip.v33i3.396

Parry, G. (2006). Recrafting work: A model for workplace engagement and meaning. University of Pennsylvania, 1-31.

Pillay, R. (2009). Retention strategies for professional nurses in South Africa. Leadership in Health Services, 22(1), 39-57. http://dx.doi.org/10.1108/17511870910928010

Pillay, R. (2010). Strategies to attract prospective students to the nursing profession. International Journal of Nursing Education Scholarship, 7(1), 1-17. http://dx.doi org/10.2202/1548-923X.1930

Porter, S. (1992). Women in a women's job: the gendered experience of nurses. Sociology of Health \& Illness, 14(4), 510-27. http://dx.doi.org/10.1111/14679566.ep10493131

Porter, L.W., Steers, R.M., Mowday, R.T., \& Boulian, P.V. (1974). Organisational commitment job satisfaction and turnover among psychiatric technicians. Journal of Applied Psychology, 59, 603-609. http://dx.doi.org/10.1037/h0037335

Rankin, J.M. \& Campbell, M.L. (2006). Managing to Nurse: Inside Canada's Health Care Reform. Toronto, Canada: University of Toronto Press.

Robbins, S.P., Odendaal, A., \& Roodt, G. (2003). Organisational behaviour. Cape Town, South Africa: Pearson Education.

Saks, A.M., \& Rothmann, J.L. (2006). Antecedents and consequences of employee engagement. Journal of Managerial Psychology, 21(7), 600-619. http://dx.doi. org/10.1108/02683940610690169

Schacklock, K., \& Brunetto, Y. (2012). The intention to continue nursing: work variables affecting three nurse generations in Australia. Journal of Advanced Nursing, 68(1), 36-46. http://dx.doi.org/10.1111/j.1365-2648.2011.05709.x

Schaufeli, W.B., \& Bakker, A.B. (2004). Job demands, job resources and their relationship with burnout and engagement - A multi-sample study. Journal of Organizational Behavior, 25, 293-315. http://dx.doi.org/10.1002/job.248

Schaufeli, W.B., Salanova, M., Gonzalez-Roma, V., \& Bakker, A.B. (2002). The measurement of engagement and burnout: a two sample confirmatory factor analytic approach. Journal of Happiness Studies, 3, 71-92. http://dx.doi.org/10.1023/A:1015630930326
Simpson, M.R. (2008). Engagement at work: A review of the literature. International Journal of Nursing Studies, 1, 1-13.

Singh, P., Jain, A.K., \& Bhandarker, A. (2006). Meaning of work in corporate India Preliminary findings. Journal of Clinical Nursing, 14(8), 90-97.

Smyer, M.A., \& Pitt-Catsouphes, M. (2007). Meaning of work for older workers. Aging Workforce, 23-30.

Steers, R.M. (1977). Antecedents and outcomes of organisational commitment. Administrative Science Quarterly, 22, 46-56. http://dx.doi.org/10.2307/2391745, PMid:10236068

Towers Perrin Talent Report. (2003). Working today: Understanding what drives employee engagement Retrieved October 05,2013, from http://www.towersperrin. $\mathrm{com} / \mathrm{tp} /$ getwebcachedoc?webc=hrs/usa/2003/200309/talent_2003.pdf

Towers Watson Company. (2012). Towers Watson Global Workforce Report. Retrieved April 23, 2013, from http://towerswatson.com/sustainable-employee-engagement

Townsend. P., \& Gebhardt. J. (2008). Employee engagement completely. Human Resource Management International Digest, 16, 22-24. http://dx.doi.org/10.1108/ 09670730810869529

Van den Heuvel, M., DemeroutiE., Schreurs, B.H.J., Bakker, A.B., \& Schaufeli, W.B. (2006) Does meaning-making help during organisational change? Career Development International, 14(6), 508-533. http://dx.doi.org/10.1108/13620430910997277

Van Zyl, L.E., Deacon, E., \& Rothmann, S. (2010). Towards happiness: Experiences of work-role fit, meaningfulness and work engagement of industrial/organisational psychologists in South Africa. SA Journal of Industrial Psychology/SA Tydskrif vir Bedryfsielkunde, 36(1), Art. \#890, 10 pages.

Welman, J.C., \& Kruger, S.J. (2001). Research methodology for the business and administrative sciences. Johannesburg, South Africa: International Thompson.

Wrzesniewski, A., McCauley, C., Rozin, P., \& Schwartz, B. (1997). Jobs, careers, and callings: People's relations to their work. Journal of research in personality, 31 21-33. http://dx.doi.org/10.1006/jrpe.1997.2162

Wu, M-L. (2010). Perceptions of work engagement of nurses in Taiwan. Texas Medical Center Dissertations. Paper AAl3445862. Retrieved April 20, 2013, from http:// digitalcommons.library.tmc.edu 